\title{
Investigating Anti-mutagenic Activities of Lantana camara L. (Verbenaceae) Applying Salmonella typhimurium and the Ames Test
}

\author{
Zahra Zare \\ Department of Biology, Farhangian University, Tehran, Iran
}

*Correspondence to

Zahra Zare,

Tel: 09125308955;

Email: zahrazarebio@gmail.com

Received March 3, 2020

Accepted July 11, 2020

Published online 30 Septemeber 2020

\begin{abstract}
Introduction: Genetic mutations have a significant role in causing cancers, and plants are effective on cancer recovery by producing metabolites. In this regard, the present study aimed to evaluate the Lantana camera anti-mutation effects applying Salmonella typhimurium in the Ames test.

Methods: To this end, the plant was prepared from the Iran National Botanical Garden in 2018 (Tehran, Iran), and the methanolic extracts of its leaves and flowers were obtained by the percolation method. Then, anti-mutagenic activities were studied by the Ames method and the assessment of the rate of reverse mutations in mutant Salmonella typhimurium. Mutant strains cannot grow on minimal mineral media thus only those bacteria that have acquired a wild genotype after reverse mutation in the presence of the mutagen are able to grow on this medium. The plant extract, along with a mutagen substance was used to evaluate its anti-mutagenic effects by counting grown colonies and calculating the mean mutation inhibitory index according to the "Ong" formula. Finally, anti-mutagenic activities were retested by adding the sterile extract of the mouse liver $\left(\mathrm{S}_{9}\right)$, and the data were analyzed by SPSS statistical software, version 22 .

Results: In general, the results showed that the mean number of grown colonies decreased significantly despite the plant material in comparison with the standard. According to the "Ong" formula, the percentage of inhibition was $[1-\mathrm{T} / \mathrm{M}] \times 100$. Based on the results, $\mathrm{T}$ grew a number of colonies on each petri dish despite the mutagen and extract, and $\mathrm{M}$ grew a number of colonies in positive control plates. Eventually, mutation inhibition percentages in leaf extracts were significantly higher than those of flower extracts, which were $75.59 \pm 0.73\left(+\mathrm{S}_{9}\right)$ and $84.79 \pm$ $0.17\left(-S_{9}\right)$, as well as $49.57 \pm 0.55\left(+S_{9}\right)$ and $62.32 \pm 0.23\left(-S_{9}\right)$, respectively $(P<0.05)$.

Conclusion: In general, the leaves and flowers of $L$. camara demonstrated anti-mutagenic activities with higher activities in the leaves compared to flowers.

Keywords: Anti-mutagenic activity, Anti-cancer activity, Lantana camara L., Ames test, Salmonella typhimurium
\end{abstract}

Please cite this article as follows: Zare Z Investigating Antimutagenic Activities of Lantana camara L. (Verbenaceae) Applying Salmonella typhimurium and the Ames Test. Int J Basic Sci Med. 2020;5(3):9095. doi: $10.34172 /$ ijbms.2020.16

\section{Introduction}

Cancers are known through unlimited and uncontrolled cell divisions, which can cause death. ${ }^{1}$ Although different methods have been introduced to treat cancers, the number of cancer patients increases annually. It is estimated that nearly 16000000 human bodies on the earth will develop this illness by the next ten years, of which about 12000000 cases are fatal. ${ }^{2}$ Accordingly, this is one of the important factors of humans dying. ${ }^{3}$ In addition, this disease is reported to be due to the lack of the regulation of important activities of the cell, including development pathways, anti-cell programmed death processes, immune responses, and cellular microenvironment. ${ }^{1,4}$

In addition, damages and genetic alterations including modifications in the DNA sequence and coherence and other genetic elements have a high impact on carcinogenesis. ${ }^{5}$

Cancer treatment has been applied to reset cellular processes. So far, several clinical experiments have studied potential treatments for cancer through radiotherapy, chemical treatment, and immunotherapy although the first two methods have harmful and lethal effects against natural

(c) 2020 The Author(s); Published by Zabol University of Medical Sciences. This is an open-access article distributed under the terms of the Creative Commons Attribution License (http://creativecommons.org/licenses/by/4.0), which permits unrestricted use, distribution, and reproduction in any medium, provided the original work is properly cited. 
tissues. ${ }^{3}$ Although the third method offers highly particular and targeted therapy, it is limited and highly expensive. ${ }^{6}$ Further, cancers recur after treatment. ${ }^{3,6}$ Recently, new methods have been used to find new compounds with anticancer effects from difficult resources for controlling the harmful effects of anticancer medicines and finding better compounds. ${ }^{3}$

Medicinal plants have long been a natural resource for the treatment of many ailments. According to the World Health Organization report, many plants are currently used for medical purposes. ${ }^{7}$

Additionally, the metabolites of plants are useful for different therapeutic aims, ${ }^{8}$ and plant compounds have biological roles such as pain reliever, along with antiinflammatory and antimicrobial activities. ${ }^{3}$ Further, they are the resources of nearly $25 \%$ of therapeutic drugs ${ }^{9}$ and more than $60 \%$ of anticancer drugs are derived from the plants. $^{10}$

As discussed earlier, it is essential to develop newer, safer, and more effective substances for treating cancer. Plant compounds are beneficial materials for developing other medicines with high performance while fewer side effects. $^{10}$

The Verbenaceae plant family includes various plant genus and species, most of which have been traditionally utilized as remedies for some disease. ${ }^{11}$ Lantana camera from the plant Verbenaceae family is endemic of Africa and America. The leaves of this plant are effective on the treatment of bellyache, wounds, rheumatism, pain in a tooth, pneumonia, and other ailments. ${ }^{12}$ Furthermore, L. camara has several biologically active compounds. Moreover, many terpenes, fatty acids, and flavonoids have been extracted from this plant in phytochemical studies. ${ }^{13,14}$ Additionally, this plant is claimed to have anti-protozoal, ${ }^{12}$ anti-bacterial, anti-fungal ${ }^{12,13}$ antioxidant, ${ }^{14}$ insecticidal, ${ }^{15}$ and anti-viral ${ }^{16}$ activities, as well as allelopathic properties. ${ }^{17}$ Similarly, the major essential compounds of $L$. camara are $\gamma$-curcumin (6.3\%), Davanone (7.3\%), germacrene D (10.9\%), $\alpha$-humulene (11.5\%), and $\beta$-caryophyllene (23.3\%). ${ }^{18}$

Considering the above-mentioned explanations, this research aimed to investigate the anti-mutagenic activities of the L. camera extract applying mutant Salmonella typhimurium through the Ames test.

\section{Materials and Methods \\ Plant Material}

Different parts of $L$. camara were prepared from the National Botanical Garden of Iran (Tehran Iran) in Spring 2018.

\section{Plant Extract}

Different parts of the plant were prepared and dried in shadow. Then, they were powdered, and $50 \mathrm{~g}$ of them were converted to the extract by adding alcohol (Methanol $80 \%)$ using the percolation method. In addition, the extracts were concentrated by a rotary system at $40^{\circ} \mathrm{C}$ (the concentrated extract was about $5 \mathrm{~g}$ ), dehydrated in the oven $\left(40^{\circ} \mathrm{C}\right)$, and finally, their anti-mutagenic activities were investigated based on the aim of the study. ${ }^{19}$

\section{Bacterial Strains}

The histidine auxotrophic mutant strains (His-) of Salmonella typhimurium (TA100) were obtained from the Laboratory of Microbiology of Kharazmy University (Tehran, Iran) and used to determine the occurrence of base-pair mutations. These mutant strains cannot grow on a minimal mineral medium, and only those bacteria having mutated to wild (His+) type by the reverse mutation in the presence of a mutagen (Sodium azide, $\mathrm{NaN}_{3}$ ) can grow on this medium. Therefore, the presence of an anti-mutagenic substance (e.g., a plant methanolic extract), along with the mutagen (i.e., $\mathrm{NaN}_{3}$ ) can reduce the rate of the reverse mutation.

\section{Anti-mutagenic Activity Assay}

The anti-mutagenic effect of the extract was evaluated by the Ames method using the mutant strain of Salmonella typhimurium (TA100) in the presence of $\mathrm{NaN}_{3}$ and counting grown colonies indicating the incidence of a reverse mutation. The mutant Salmonella typhimurium strain (TA100) that requires histidine for growing in minimal media is suitable for measuring the antimutagenic activity of mutagenic substances..$^{20-22}$

In this phase, the anti-mutagenic effect of the extract was evaluated by adding $\mathrm{S}_{9}$ (The sterile extract of the mouse liver containing microsomal enzymes). The cytochrome oxidase enzyme (P450), which inactivates oxidant and toxic compounds, can be found in the membrane of liver cells, especially the endoplasmic reticulum membrane). Thus, the metabolic and antimutagenic activities of compounds are strengthened in the presence of the microsomal extract of the liver $\left(\mathrm{S}_{9}\right)$.

The concentration of $1 \%$ or $1 \mu \mathrm{g} / \mathrm{mL}$ of the concentrated extract was used because of its suitability for assaying antimutagenic activity without killing the bacteria. Then, the anti-microbial activity of the methanolic extract against Salmonella typhimurium was assessed by the microbial culture and the disk diffusion method to obtain the minimum inhibitory concentration, which was obtained $6.25 \mu \mathrm{g} / \mathrm{mL}$ for both leaf and flower extracts. Further, Dimethyl sulfoxide was considered as the solvent. ${ }^{19}$

Next, the anti-mutagenic test was performed by adding the plant extract $(0.5 \mathrm{~mL})$ to the fresh overnight culture $(0.5 \mathrm{~mL})$ and the Histidine-Biotin solution $(0.5 \mathrm{~mL})$ containing top agar $(10 \mathrm{~mL})$ and $\mathrm{NaN}_{3}(1.5 \mu \mathrm{g})$ in a test tube. The contents of this tube were shaken for 3 seconds by a shaker and then evenly spread on the entire surface of the minimal glucose agar medium. Then, the experiment was repeated three times, and petri dishes were placed in an incubator (at $37^{\circ} \mathrm{C}$ for 24 hours)..$^{21,22}$

The positive control contained $\mathrm{NaN}_{3}(1.5 \mu \mathrm{g})$ as a 
mutagen per plate, and plates without any $\mathrm{NaN}_{3}$ or the plant extract, which only consisted of $0.5 \mathrm{~mL}$ sterile distilled water, were considered as the negative control. After the incubation, grown colonies were counted per plate. ${ }^{21-23}$

In the second experiment, $0.5 \mathrm{~mL}$ of the $\mathrm{S}_{9}$ compound (prepared from the laboratory complex of the Islamic Azad University of Tehran, Science and Research Branch) was added to all plates.

\section{Calculating the Percentage of Mutation Inhibition}

The average number of grown colonies per plate was determined, and the mean mutation inhibitory activity was calculated by the "Ong" formula. ${ }^{24}$ This formula computes the percentage of mutation inhibition based on the number of the grown colonies per plate as follows:

\section{Percentage of inhibition $=[1-T / M] \times 100$}

where $T$ denotes the numbers of the grown colonies each petri with the mutagen and the plant extract, and $M$ represents the number of grown colonies in the plates of the positive control. The mutagenicity of $\mathrm{NaN}_{3}$ without the extract (positive control) was considered as $100 \%$ growth (i.e., $0 \%$ mutation inhibitory activity). ${ }^{21}$

Finally, the anti-mutagenic activity was categorized as moderate $(25 \%-40 \%)$ or strong (>40\%)..$^{18,21,25}$

\section{Analysis of Data}

The findings were presented as the mean \pm standard deviation of three replications per sample in each experiment. Furthermore, any significant difference between the mean of the grown colonies per petri dish was analyzed by SPSS statistical software (version 22) using the one-way analysis of variance, and the significance level was considered as $P<0.05$.

\section{Results}

The present study assessed the anti-mutagenic activities of plant extracts applying the mutated Salmonella typhimurium (TA100) strain.

Positive control plates, including sodium azide $\left(\mathrm{NaN}_{3}\right)$, were used to induce reverse mutations. $\mathrm{NaN}_{3}$ converts several mutant bacteria into wild types (these bacteria can grow on the minimal mineral medium without histidine). Moreover, negative control plates, including distilled water without the presence of $\mathrm{NaN}_{3}$, were applied to induce spontaneous mutations, and the resulting colonies indicated that several bacteria in the medium spontaneously mutated and became wild. In this case, the number of colonies is extremely low compared to the positive control (Figure 1, a-b) and is negligible.

The number of the grown colonies in plates containing the extracts was lower compared to the positive control due to the anti-mutagenic activities of the plant extracts that inhibited the reverse mutations of bacteria in the presence of $\mathrm{NaN}_{3}$ (Figure 1, c-f).

The number of the grown colonies and the percentage of mutation inhibition calculated by the Ong formula ${ }^{24}$ are presented in Table 1.

\section{Anti-mutagenic Activity of Lantana camara Leaf Methanolic Extract}

The statistical results of the anti-mutagenic activities of the leaf methanolic extract in the absence of $\mathrm{S}_{9}$ showed that the number of the colony-forming unit (CFU) of the mean grown colonies $(201.66 \pm 4.83)$ significantly decreased compared to the control $(P<0.05)$, and

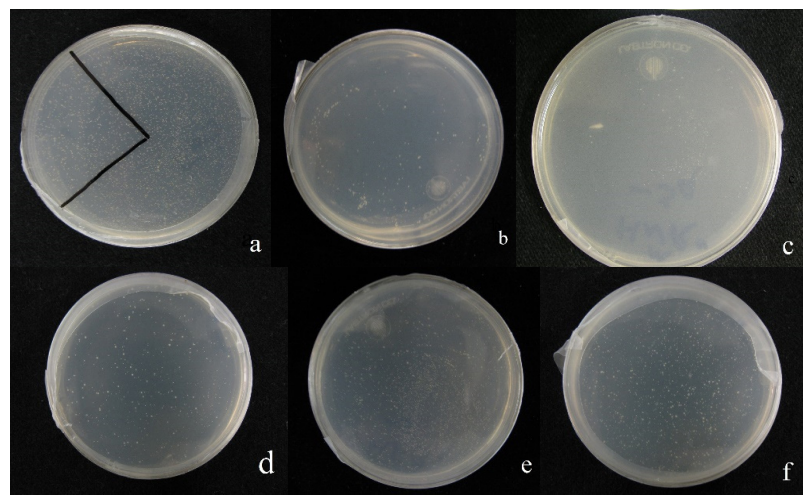

Figure 1. Anti-mutagenic Activity of the Lantana camera Extract. The images of the grown colonies in the positive control (a), negative control (b), treatment with the leaf extract in the presence of $\mathrm{S}_{9}(\mathrm{c})$, treatment with the leaf extract without $\mathrm{S}_{9}(\mathrm{~d})$, treatment with the flower extract in the presence of $S_{9}(e)$, and treatment with the flower extract without $\mathrm{S}_{9}(\mathrm{f})$

Table 1. The Effects of the Leaf and Flower Methanolic Extracts of Lantana camera on the Number of the Grown Colonies of Salmonella typhimurium TA100 (by Reverse Mutations) and Mutation Inhibition Percentage With or Without $\mathrm{S}_{\mathrm{g}}$

\begin{tabular}{|c|c|c|c|c|}
\hline \multirow[b]{2}{*}{ Sample } & \multicolumn{2}{|c|}{$\begin{array}{c}\text { TA100 } \\
+s_{9}\end{array}$} & \multicolumn{2}{|c|}{$\begin{array}{c}\text { TA100 } \\
-s_{9}\end{array}$} \\
\hline & Mutation inhibition percentage & $\begin{array}{c}\text { Mean number of grown } \\
\text { colonies }\end{array}$ & Mutation inhibition percentage & $\begin{array}{c}\text { Mean number of grown } \\
\text { colonies }\end{array}$ \\
\hline Positive control & - & $826.33 \pm 3.02$ & - & $826.33 \pm 3.02$ \\
\hline Negative control & - & $102.66 \pm 4.98$ & - & $102.66 \pm 4.98$ \\
\hline Leaves extract & $84.79 \pm 0.17^{*}$ & $125.66 \pm 1.37$ & $75.59 \pm 0.73^{* *}$ & $201.66 \pm 4.83$ \\
\hline Flower extract & $62.32 \pm 0.23^{*}$ & $311.33 \pm 1.68$ & $49.57 \pm 0.55^{* *}$ & $416.66 \pm 3.38$ \\
\hline
\end{tabular}

Note. $\mathrm{S}_{9}$ : Sterile extract of the mouse liver containing microsomal enzymes.

"A significant difference was at $P=0.026$, at the level of $5 \% * *$ Significant difference was at $P=0.018$ at the level of $5 \%$. 
mutation inhibition percentage was calculated as $75.59 \pm$ 0.73 . Additionally, strong anti-mutagenic activity (above $40 \%$ ) was observed according to the standard "Ong" formula. $^{24}$

In addition, the mean number of the grown colonies of this extract in anti-mutagenic studies in the presence of $\mathrm{S}_{9}$ demonstrated a significant decrease $(125.66 \pm 1.37 \mathrm{CFU}$, $P<0.05)$ compared with the positive control, showing a percentage of mutation inhibition of $84.79 \pm 0.17$ (Figures 2 and 3). As shown in Figure 2, the anti-mutagenic effect with $\mathrm{S}_{9}$ was higher compared to the absence of $\mathrm{S}_{9}$.

\section{Anti-mutagenic Activity of Lantana camara Flower Methanolic Extract}

Based on the results, the mean grown colonies significantly decreased $(416.66 \pm 3.38) \mathrm{CFU}$ in the presence of the flower methanolic extract and the absence of $\mathrm{S}_{9}(P$ $<0.05)$ compared with the positive control. Further, the mutation inhibition percentage was $49.57 \pm 0.55$ and antimutagenic was above $40 \%$ although it was significantly lower compared to the leaf extract $(P=0.018)$.

In the presence of $S_{9}$, the mean number of the grown colonies of the flower extract showed a significant decrease $(311.33 \pm 1.68 \mathrm{CFU}$ and $P<0.05)$ compared with the control. Furthermore, the percentage of mutation inhibition was $62.32 \pm 0.23$, and anti-mutagenic activity was also above $40 \%$ although it was significantly lower than that of the leaf extract $(P=0.026)$.

\section{Discussion}

The bacterial reverse mutation assay is a simple, rapid, and inexpensive assay for the detection of the mutagenic and anti-mutagenic activities of different substances. The damage of DNA by mutagens may be the main cause of most genetic defects and cancer. In addition,

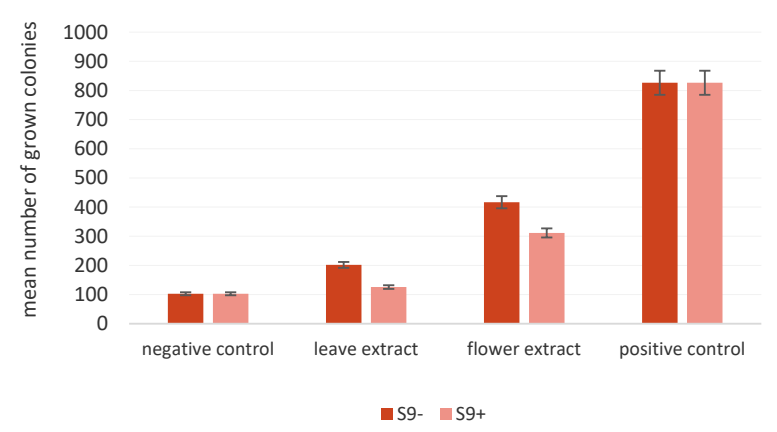

Figure 2. Comparison of the Mean Number of Grown Colonies Between the Extracts of Lantana camara With the Control With $\mathrm{S}_{9}$ $\left(+\mathrm{S}_{9}\right)$ and Without $\mathrm{S}_{9}\left(-\mathrm{S}_{9}\right) \pm$ standard error.

Note. The comparison was made at the 0.05 level. $\mathrm{S}_{9}$ is a sterile extract of the mouse liver containing microsomal enzymes such as the cytochrome oxidase enzyme (P450) which causes the antitoxic action and inactivates oxidant and cancer compounds. In addition, the positive control contained sodium azide $\left(\mathrm{NaN}_{3}\right)$ as a mutagen per plate, and plates consisting of only sterile distilled water without any $\mathrm{NaN}_{3}$ or the plant extract were considered as negative control.

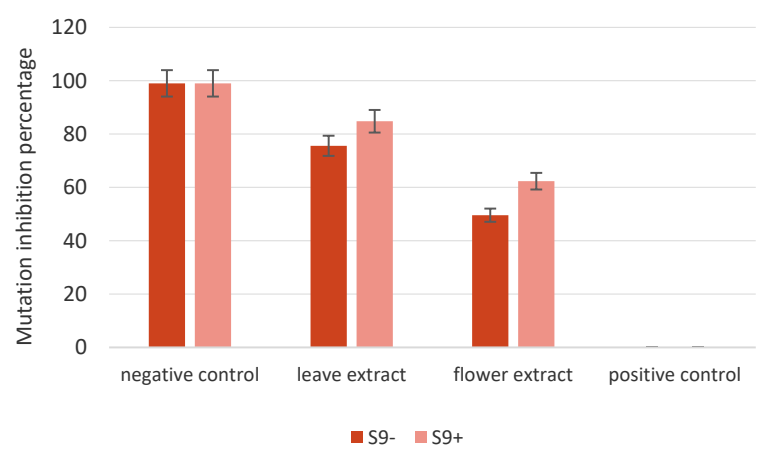

Figure 3. Comparison of the Percentage of Mutation Inhibition Between the Extracts of $L$. camara With the Control With $\mathrm{S}_{9}\left(+\mathrm{S}_{9}\right)$ and Without $\mathrm{S}_{9}\left(-\mathrm{S}_{9}\right) \pm$ Standard Error

Note. L. camera: Lantana camera. The comparison was made at the 0.05 level. $\mathrm{S}_{9}$ is a sterile extract of the mouse liver containing microsomal enzymes such as the cytochrome oxidase enzyme (P450) which causes the antitoxic action and inactivates oxidant and cancer compounds. Further, the positive control contained sodium azide $\left(\mathrm{NaN}_{3}\right)$ as a mutagen per plate, and plates consisting of only sterile distilled water without any $\mathrm{NaN}_{3}$ or the plant extract were considered as negative control.

the anti-mutation and anti-cancer activities of plants are due to their secondary metabolites. ${ }^{26}$ Further, the plant structures of $L$. camara have many of these compounds which are accountable for several medical properties for treating diseases such as cancers, measles, chickenpox, asthma, edema, blood pressure, eczema, eye infections, tetanus, and malaria. ${ }^{27}$

These research findings represented that L. camara methanolic extracts had anti-mutation activities by applying the Salmonella typhimurium reverse mutation assay and the Ames test, which is in line with the results of Zare et al on the anti-mutation and anti-cancer activities of two species from the Verbenaceae family (Lippia genus), namely, Lippia citriodora and Lippia nodiflora, which were attributed to their flavonoids and essential oil components. ${ }^{28}$ Furthermore, Begum et al reported the existence of flavonoids as the components of L. camara. ${ }^{29}$

Our results are also in conformity with those of Ghasemian et al, demonstrating the effects of secondary metabolites on the anti-mutagenic and anti-oxidant activities of the pomegranate peel extracts of two cultivars (from Iran) using the Ames test. They also suggested that the existence of flavonoid compounds in these plants was responsible for these activities. ${ }^{21}$ Additionally, Ruberto and Baratta reported the anti-oxidant and anti-cancer activities of phenolic compounds. ${ }^{30}$ Meanwhile, phenolic compounds are found to be the major constituents in the plants of the Verbenaceae family, including L. camara, ${ }^{31}$ which can explain its anti-mutagenic activity.

In another study, Vicuña et al concluded that essential oils or fatty compounds (e.g., terpenoids) in the Verbenaceae family are responsible for anti-tumor and anti-carcinogenic effects by augmenting DNA repair mechanisms. ${ }^{32}$ Moreover, Sefidkon indicated 
that the vegetative and reproductive parts of L. camara, which were planted in Iran, contained essential oils and fatty compounds including $\beta$-caryophyllene $(14.0 \%$ and $22.5 \%)$, sabinene $(16.5 \%$ and $7.3 \%), 1,8$-cineole $(10.0 \%$ and $6.0 \%)$, humulene $(6.0 \%$ and $10.8 \%)$, and bicyclogermacrene $(8.1 \%$ and $18.5 \%) .{ }^{33}$ Therefore, the existence of the essential oils can partly be involved in the observed anti-mutagenic and anti-cancer activities of $L$. camara as well.

According to our results, the leaf extract demonstrated the highest anti-mutagenic effects in the presence of $\mathrm{S}_{9}$ $\left(+S_{9}\right)$. Effective compounds (i.e., essential oil, flavonoid, and the like) are probably more abundant in the leaves as compared to the flowers of the plant, or the types of the compounds in the flowers probably differ from those of the leaves, which needs to be studied and analyzed in the future.

\section{Conclusion}

Generally, the findings of the research showed that the L. camara methanolic extracts of its flowers and leaves had potent anti-mutagenic activity against Salmonella typhimurium. These activities are probably related to the existence of flavonoids and different fatty compounds in this plant. The findings revealed that anti-mutagenic activity was higher in the leaf extract compared to the flowers. Thus, it is suggested that future studies directly investigate the anti-cancer activities of this plant on human and animal cancer cell lines.

\section{Ethical Approval}

Not applicable. There was no need for moral confirmation considering that bacterial samples were used in this study.

\section{Conflict of Interest Disclosure}

The authors declare that there is no conflict of interests.

\section{Acknowledgments}

The author would like to thank the officials of the Laboratory Complex of the Islamic Azad University of Tehran, Science and Research Branch for any support.

\section{References}

1. Lee CS, Baek J, Han SY. The role of kinase modulators in cellular senescence for use in cancer treatment. Molecules. 2017;22(9). doi:10.3390/molecules22091411

2. Amin AR, Kucuk O, Khuri FR, Shin DM. Perspectives for cancer prevention with natural compounds. J Clin Oncol. 2009;27(16):2712-2725. doi:10.1200/jco.2008.20.6235

3. Shin SA, Moon SY, Kim WY, Paek SM, Park HH, Lee CS. Structure-based classification and anti-cancer effects of plant metabolites. Int J Mol Sci. 2018;19(9). doi:10.3390/ ijms19092651

4. Gali-Muhtasib H, Hmadi R, Kareh M, Tohme R, Darwiche N. Cell death mechanisms of plant-derived anticancer drugs: beyond apoptosis. Apoptosis. 2015;20(12):15311562. doi:10.1007/s10495-015-1169-2
5. Ames BN, Durston WE, Yamasaki E, Lee FD. Carcinogens are mutagens: a simple test system combining liver homogenates for activation and bacteria for detection. Proc Natl Acad Sci U S A. 1973;70(8):2281-2285. doi:10.1073/ pnas.70.8.2281

6. Morrissey KM, Yuraszeck TM, Li CC, Zhang Y, Kasichayanula S. Immunotherapy and novel combinations in oncology: current landscape, challenges, and opportunities. Clin Transl Sci. 2016;9(2):89-104. doi:10.1111/cts.12391

7. Scorzoni L, Benaducci T, Fusco Almeida AM, Siqueira Silva DH, da Silva Bolzani V, Mendes Gianinni JMS. The use of standard methodology for determination of antifungal activity of natural products against medical yeasts Candida sp and Cryptococcus sp. Braz J Microbiol. 2007;38(3):391397. doi:10.1590/S1517-83822007000300001

8. Korkina L, Kostyuk V. Biotechnologically produced secondary plant metabolites for cancer treatment and prevention. Curr Pharm Biotechnol. 2012;13(1):265-275. doi:10.2174/138920112798868692

9. Schmidt BM, Ribnicky DM, Lipsky PE, Raskin I. Revisiting the ancient concept of botanical therapeutics. Nat Chem Biol. 2007;3(7):360-366. doi:10.1038/nchembio0707-360

10. Gordaliza M. Natural products as leads to anticancer drugs. Clin Transl Oncol. 2007;9(12):767-776. doi:10.1007/ s12094-007-0138-9

11. Pascual ME, Slowing K, Carretero E, Sánchez Mata D, Villar A. Lippia: traditional uses, chemistry and pharmacology: a review. J Ethnopharmacol. 2001;76(3):201-214. doi:10.1016/s0378-8741(01)00234-3

12. Deena MJ, Thoppil JE. Antimicrobial activity of the essential oil of Lantana camara. Fitoterapia. 2000;71(4):453-455. doi:10.1016/s0367-326x(00)00140-4

13. Begum S, Zehra SQ, Siddiqui BS. Two new pentacyclic triterpenoids from Lantana camara LINN. Chem Pharm Bull (Tokyo). 2008;56(9):1317-1320. doi:10.1248/ cpb.56.1317

14. Verma DK, Singh SK, Tripathi V. A rare antibacterial flavone glucoside from Lantana camara. Indian Drugs. 1997;34:32-35.

15. Dua VK, Pandey AC, Dash AP. Adulticidal activity of essential oil of Lantana camara leaves against mosquitoes. Indian J Med Res. 2010;131:434-439.

16. García CC, Acosta EG, Carro AC, et al. Virucidal activity and chemical composition of essential oils from aromatic plants of central west Argentina. Nat Prod Commun. 2010;5(8):1307-1310.

17. Verdeguer M, Blázquez MA, Boira H. Phytotoxic effects of Lantana camara, Eucalyptus camaldulensis and Eriocephalus africanus essential oils in weeds of Mediterranean summer crops. Biochem Syst Ecol. 2009;37(4):362-369. doi:10.1016/j.bse.2009.06.003

18. Sousa EO, Almeida TS, Menezes IRA, et al. Chemical composition of essential oil of Lantana camara L. (Verbenaceae) and synergistic effect of the aminoglycosides gentamicin and amikacin. Rec Nat Prod. 2012;6(2):144150 .

19. Manikandan T, Neelakandan T, Rani GU. Antibacterial activity of Salicornia brachiata, a halophyte. J Phycol. 2009;1(6):441-443. 
20. Mortelmans K, Zeiger E. The Ames Salmonella/microsome mutagenicity assay. Mutat Res. 2000;455(1-2):29-60. doi:10.1016/s0027-5107(00)00064-6

21. Ghasemian A, Mehrabian S, Majd A. Peel extracts of two Iranian cultivars of pomegranate (Punica granatum) have antioxidant and antimutagenic activities. Pak J Biol Sci. 2006;9(7):1402-1405. doi:10.3923/pjbs.2006.1402.1405

22. Abdul-Hafeez EY, Karamova NS, Ilinskaya ON. Evaluation of mutagenic and antimutagenic potential of stem bark aqueous extracts of eight trees by the bacterial reverse mutation assay. Ekol Genet. 2018;16(3):55-61. doi:10.17816/ecogen16355-61

23. Negi PS, Jayaprakasha GK, Jena BS. Antioxidant and antimutagenic activities of Pomegranate peel extracts. Food Chem. 2003;80(3):393-397. doi:10.1016/S03088146(02)00279-0

24. Ong TM, Whong WZ, Stewart J, Brockman HE. Chlorophyllin: a potent antimutagen against environmental and dietary complex mixtures. Mutat Res. 1986;173(2):111115. doi:10.1016/0165-7992(86)90086-2

25. Ghaly Yousif M, Mayar Hezam A. Using of Salmonella typhimurium as a test for the detection of carcinogens in foods in Iraq. Biosci Res. 2019;16(1):677-682.

26. Rahman M, Rahman A, Alamgir ANM. Screening of anticancer medicinal plants for secondary metabolites. J Pharmacogn Phytochem. 2016;5(4):100-103.
27. Leonare MK, Sharma M, Hajare SW, Borekar VI. Lantana camara: overview on toxic to potent medicinal properties. Int J Pharm Sci Res. 2012;3(9):3031-3035.

28. Zare Z, Antimutation, and anticancer activities of two species Lippia citriodora and Lippia nodiflora (Verbenaceae). 6th National Congress of Medicinal Plants; Tehran, 11-12 May, 2017.

29. Begum S, Wahab A, Siddiqui BS. Antimycobacterial activity of flavonoids from Lantana camara Linn. Nat Prod Res. 2008;22(6):467-470. doi:10.1080/14786410600898714

30. Ruberto G, Baratta MT. Antioxidant activity of selected essential oil components in two lipid model systems. Food Chem. 2000;69(2):167-174. doi:10.1016/s03088146(99)00247-2

31. Rana VS, Prasad D, Blazquez MA. Chemical composition of the leaf oil of Lantana camara. J Essent Oil Res. 2005;17(2):198-200. doi:10.1080/10412905.2005.9698874

32. Vicuña GC, Stashenko EE, Fuentes JL. Chemical composition of the Lippia origanoides essential oils and their antigenotoxicity against bleomycin-induced DNA damage. Fitoterapia. 2010;81(5):343-349. doi:10.1016/j. fitote.2009.10.008

33. Sefidkon F. Essential oil of Lantana camara L. occurring in Iran. Flavour Fragr J. 2002;17(1):78-80. doi:10.1002/ ffj. 1048 